\title{
Analysis of the Degradation Condition of Elementary Schools
}

\author{
Sónia Raposo \\ Buildings Department, Laboratório Nacional de Engenharia Civil, Av. do Brasil 101, 1700-066 \\ Lisboa, Portugal, sraposo@lnec.pt
}

\begin{abstract}
Currently, there is still no information regarding the performance of public buildings after their construction and the relationship with the needs for carrying out maintenance activities. This paper presents some of the main anomalies detected in six schools, built between 1997 and 2003 in Lisbon. The analysis of the degradation condition of these schools was based on data obtained through detailed visual inspections, carried out in three distinct periods of their operation phase, 2007, 2013 and 2018. The highest level of severity mainly concerns defects on buildings structure and buildings envelope and results from bad decisions made during design and/or construction. Therefore, there are serious problems related to the premature deterioration of these educational buildings, requiring expensive, complex and unplanned major repairs to achieve their specified design service life. This work highlights the need for greater involvement of school building management entities, in the early stages of the building process, including design, tendering, construction and handover.
\end{abstract}

Keywords: Elementary School, Building Condition, Anomalies, Durability.

\section{Introduction}

The building condition assessment (BCA) is a systematic inspection, review, and report on the state of a building's structure, construction elements and systems. The BCA provides an identification of elements anomalies and the expected costs to remedy those deficiencies. This is an important step for the management of buildings maintenance and should be applied to the existing elementary public school portfolio of Lisbon. This network of schools includes more than 100 buildings with construction ages ranging from the nineteenth century to the beginning of this century (Raposo, 2011). Despite the existence of schools operating in very old buildings, are the most recent schools, built after 1980, that present major problems of conservation and maintenance (Raposo et al., 2008).

In the present paper, the results obtained through visual inspection of six school establishments, built between 1997 and 2003, are presented. Inspections were carried out in 2007, 2013 and 2018 and it was possible to identify some recurring anomalies and causes for the accelerated and premature degradation that occurs in these buildings.

\section{Research Methodology}

In 2007 Raposo, Fonseca and Brito (2008) carried out a preliminary research on six elementary school of recent construction in Lisbon. The work was developed in two phases: (i) collection and treatment of information from the design phase and from the use and operation phase, (ii) fieldwork with detailed visual inspection of the buildings. In 2013 an inspection and BCA was performed of the building's structural and envelope components and playgrounds and outdoor spaces (Luís, 2013), and of the building's interior elements, including finishes, walls, ceilings, doors and plumbing (Nogueira, 2013). In 2018, the National Laboratory for Civil Engineering 
carry out an assessment of the maintenance condition of 55 kindergarten $(\mathrm{k})$ and elementary schools (EB1), for the Municipality of Lisbon (Vilhena et al. 2019). Extensive and detailed photographic and written records were made about anomalies detected allowing its comparison over time.

Table 1 shows the building characteristics of Prista Monteiro School (PM), Vale de Alcântara School (VA), Alto da Faia School (AF), Padre Rocha e Melo School (PRM), Alta de Lisboa School (AL) and Vasco da Gama School (VG) integrating the kindergarten and three levels of basic education.

Table 1. School Buildings Characteristics.

\begin{tabular}{ccccccc}
\hline Schools & Year & Pupils & Level & GA $(\mathrm{m} 2)$ & Floors & Year of Inspection \\
\hline PM & 1997 & 110 & EB1 & 2200 & 2 & $2007-2018$ \\
\hline VG & 1999 & 600 & $\mathrm{k}+\mathrm{EB} 1 / 2 / 3$ & 8800 & 3 & $2007-2018$ \\
\hline VA & 2001 & 130 & $\mathrm{k}+\mathrm{EB} 1$ & 1700 & 2 & $2007-2018$ \\
\hline AF & 2001 & 340 & $\mathrm{k}+\mathrm{EB} 1$ & 4000 & 3 & $2007-2013-2018$ \\
\hline PRM & 2002 & 330 & $\mathrm{k}+\mathrm{EB} 1$ & 3000 & 2 & $2007-2018$ \\
\hline AL & 2003 & 330 & $\mathrm{k}+\mathrm{EB} 1$ & 3300 & 2 & $2007-2013-2018$ \\
\hline & & & & &
\end{tabular}

\section{Results}

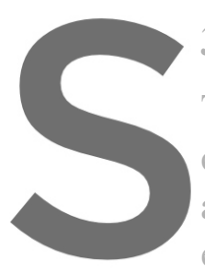

\subsection{Foundation and Structure The structure of VA School bui concrete. The inspection anomalies in the structu existence of wide openin g cracks in multiple w
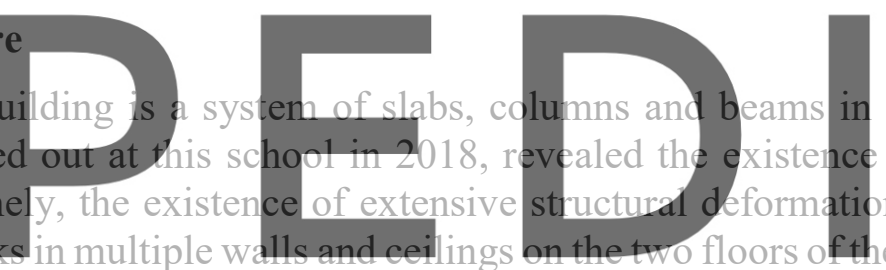

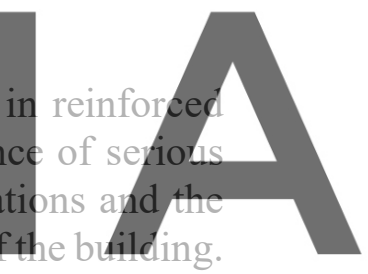

Figure 1 shows the result obtained through inspections carried out in 2007 and 2018, where

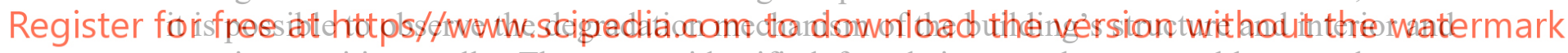
exterior partition walls. They were identified foundations settlement problems and water infiltration through the roof in several classrooms (Vilhena et al., 2019). Following this inspection, the school was closed for further rehabilitation intervention.
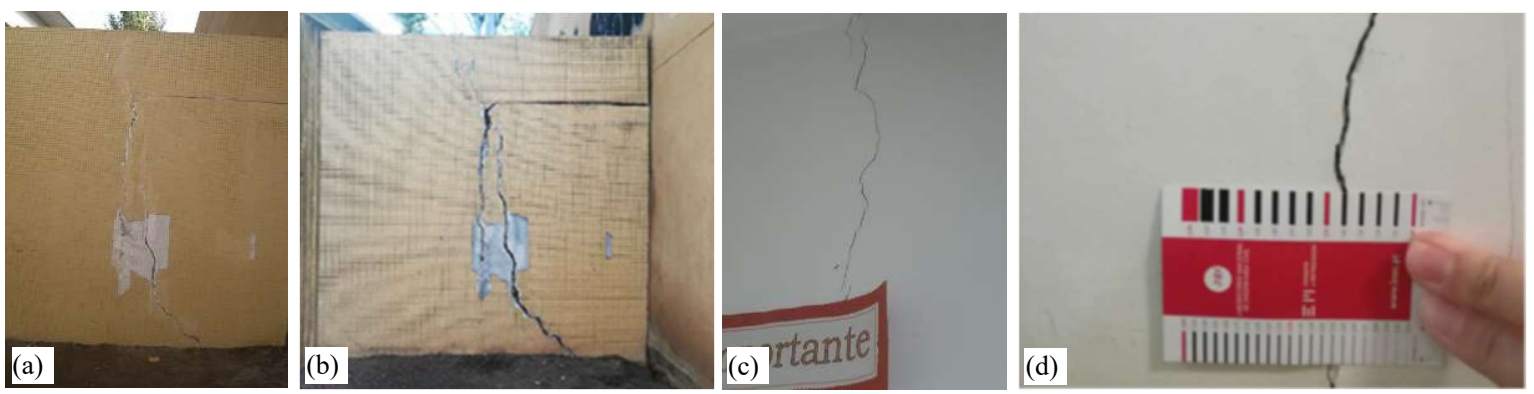

Figure 1. VA School: deterioration process of the exterior partition wall in 2007 (a) and 2018 (b). Cracks in walls in 2007 (c) and 2018 (b).

The 2018 survey, carried out in AF school, revealed the existence of anomalies in the outdoor constructive elements. The most frequent anomalies in these elements are oriented cracking, 
severe fracture, differential settlements and deteriorated expansion joints without sealant. Some of these defects were detected since 2007, when only six years had passed on handover of the building. Figure 2 shows the result obtained through inspections carried out in 2007, 2013 and 2018, on the supporting wall located in AF school's outdoor spaces. It is possible to observe the existence of settlements and structural movements that remain unsolved.
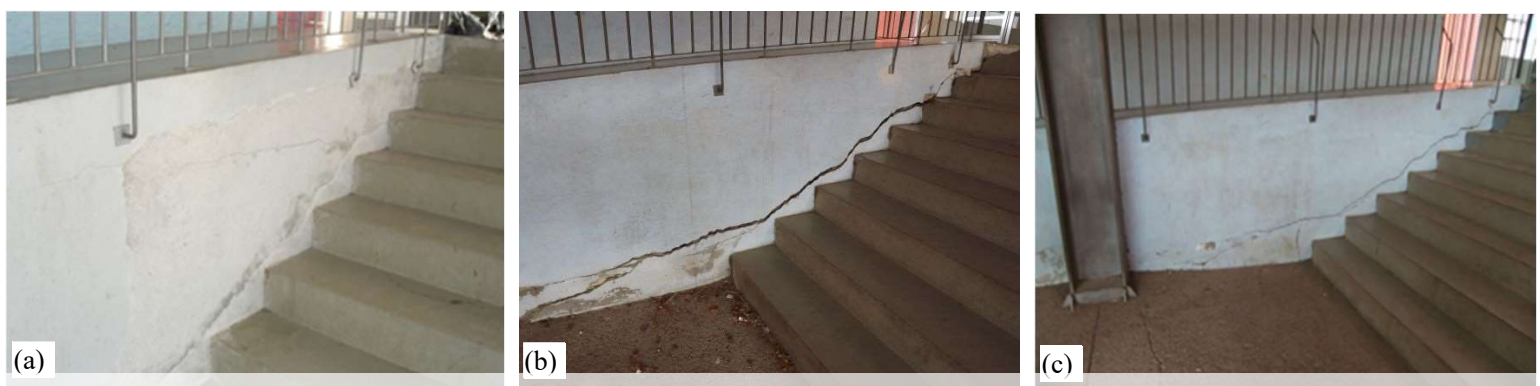

Figure 2. AF School-outdoor spaces: deformation and settlement of the supporting wall and the recurring appearance of cracks. Anomaly evolution in 2007 (a), 2013 (b) and 2018 (c).

AL School was implanted on a landfill site, which is very steep along the longitudinal and transversal development of the building. The building structure is in reinforced concrete and is made of two blocks connected by an access ramp and stairs. In 2007, the existence of several anomalies resulting from the differential settlement of the two blocks was already visible (cracking in walls and broken elements). Although several repairs have been carfied out in the building, 2013 and 2018 cracks in the walls an deteriorated expansion jo Lack of repair of the joints exposes the building elements
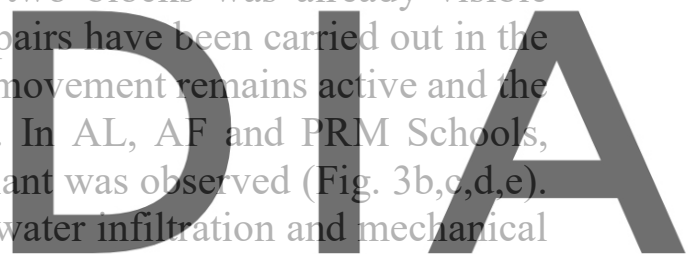
actions.

Register for free at https//www.scipedia.com to download the version without the watermark
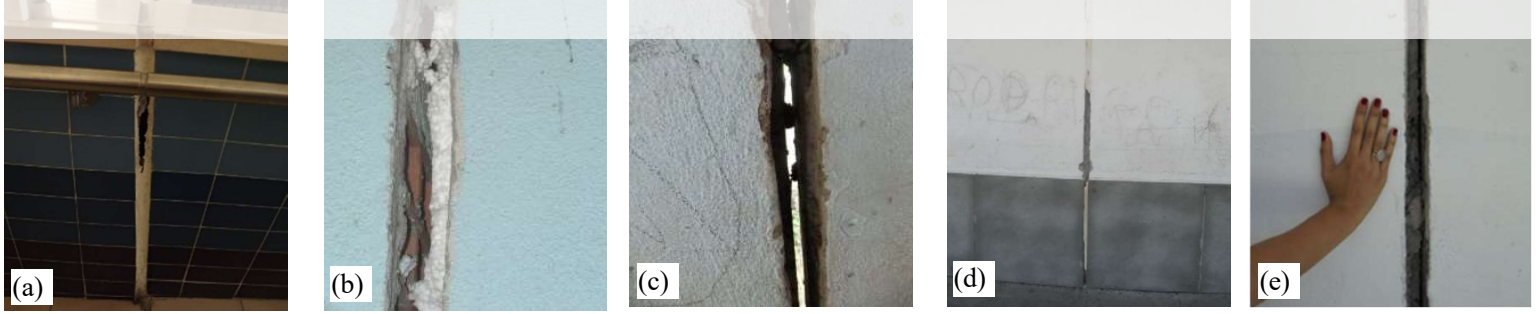

Figure 3. AL School: foundation settlement movement: broken stone and construction joint opening in 2013 (a). Expansion joints without sealant: AF School in 2007 (b) and 2018 (c); PRM School in 2007 (d) and 2018 (e).

\subsection{Building Envelope}

\subsubsection{Roofs}

Three of the six buildings have flat roofs (PRM, AL and VA schools), AF school presents a mixture of flat and sloping roofs in metal sheet, PM school present a sloping roof covered with 
ceramic tiles, and VG School presents a non-traditional roof covering made of ceramic pellets. In PM School, infiltrations water problems continue to be observed since 2007 survey, in the area of the gymnasium affecting both the ceiling and the floor. The AF School continues to present problems between the several flat and sloped roofs boundary buildings (Fig. 4a). Skylights are the element that most frequently presents anomalies caused by water infiltration. It was possible to observe the degradation mechanism in ceilings, walls and floor coatings, caused by water infiltration through skylights in PMR School (Fig. 4b,c).
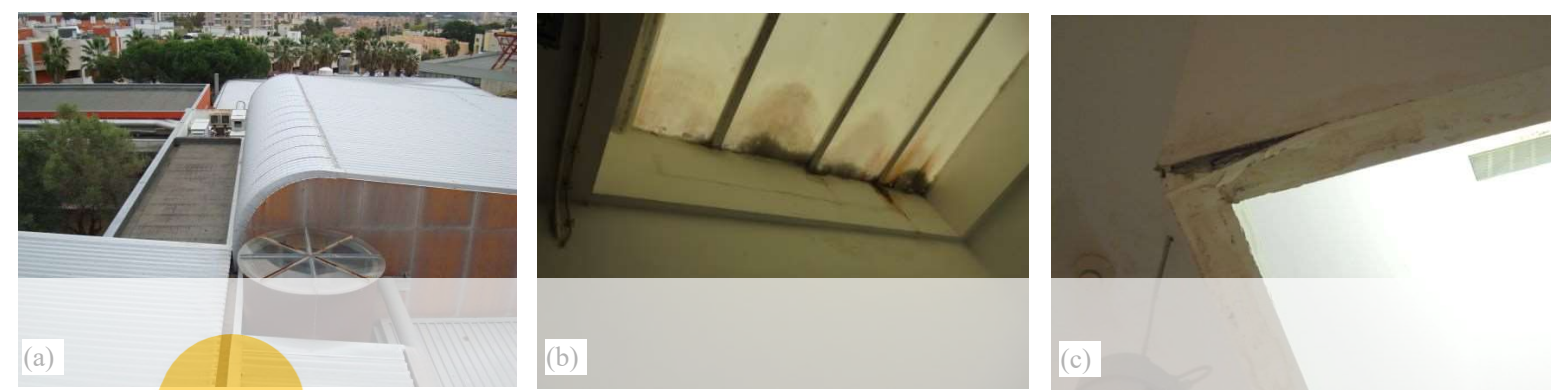

Figure 4. AF School: mixture of flat and sloping roofs in metal sheet (a). Water infiltration problems betewen the building's roofs. PMR School skylights problems in 2018 (b), (c).

\subsubsection{Exterior walls, windows and doors}
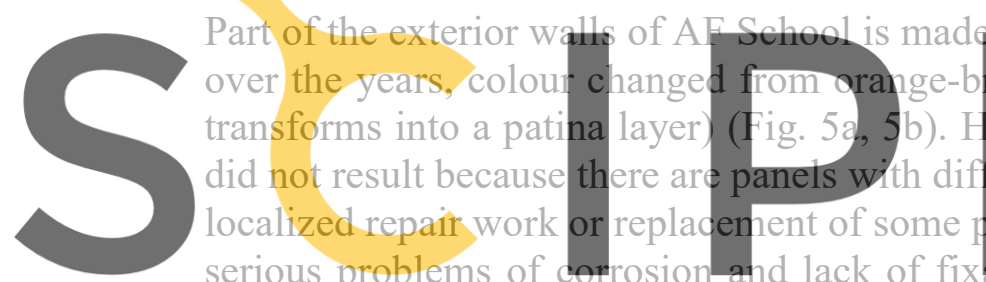
serious problems of

PRM School, the cladding of ventilated facades in wooden panels presented several anomalies

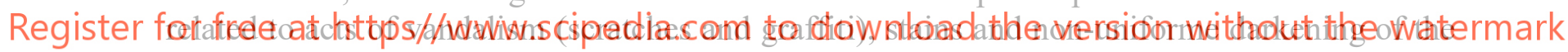
surface and unequal joint opening (with large local openings) without any filling (Fig. 5d,e) exposing the building elements to water infiltration.
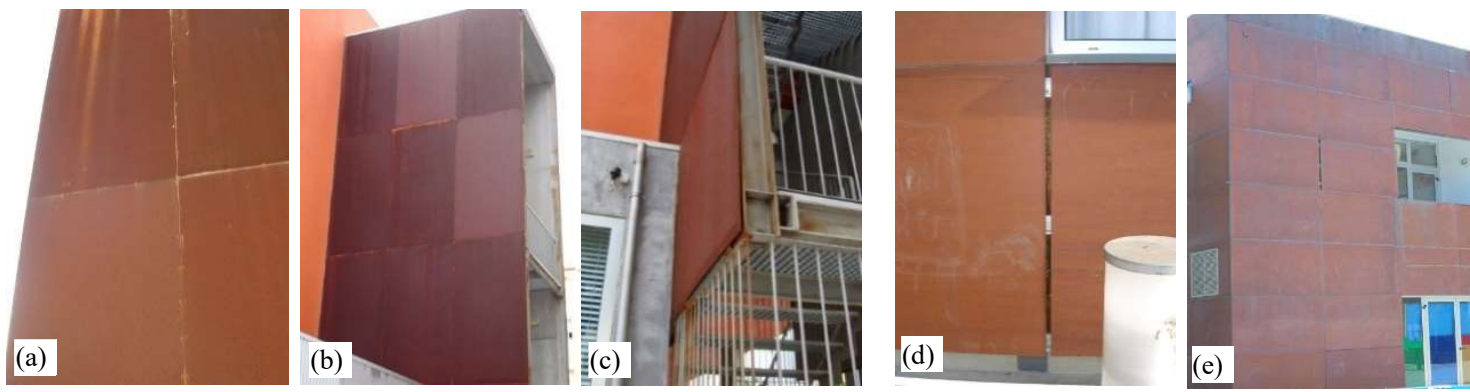

Figure 5. AF School - exterior walls in Corten steel panels: colour change from 2007 (a) to 2018 (b). Corrosion and fixation problems in panels in 2018 (c). PRM School wooden panels degradation in 2007 (d) and in 2018 (e) with 16 years of service life.

In PRM School, damaged or missing door locks and handles were observed in the surveys. These failures severely reduces the adequate serviceability of the exterior doors (Fig. 6a,b). 
These anomalies were detected in 2007 in doors with 5 years of service life. In general, some problems with rain penetration were observed in windows and non-operational interior polystyrene blinds is a very frequent anomaly. In AF School the outdoors shading were broken and deformed caused by its proximity to the playing field (Fig. 6c,d).
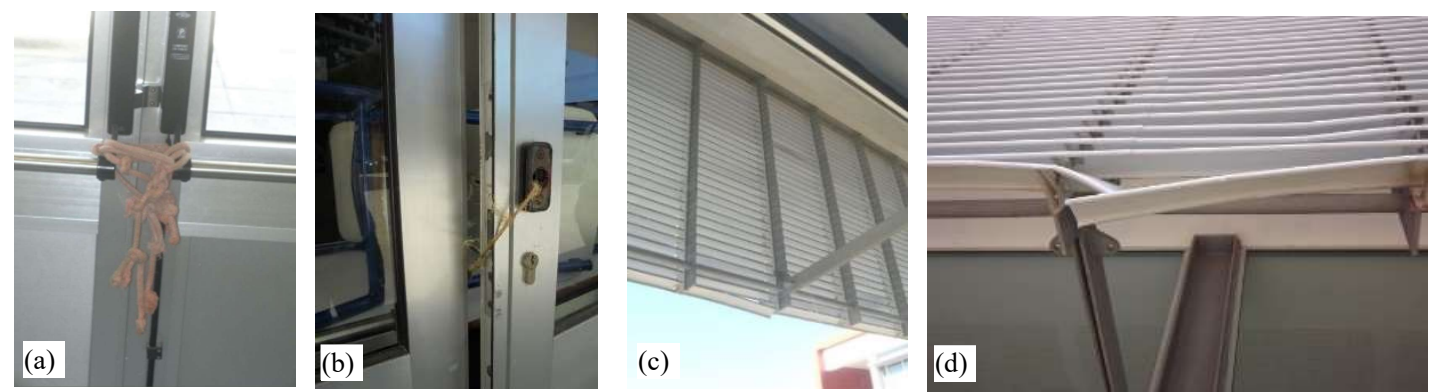

Figure 6. PRM School: missing door locks and handles 2007 (a) and 2018 (b). AF School: outdoors shading broken and deformed in 2007 (c) and 2018 (d).

\subsection{Building Interior}

\subsubsection{Floors, walls, ceilings and doors}

At PRM School, the degradation mechanism of the floor finishes, in the arts and crafts areas,

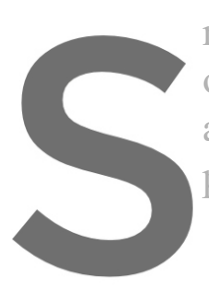
next to the classroom observed since the 200 area was observed. Figu process caused by wet-dr
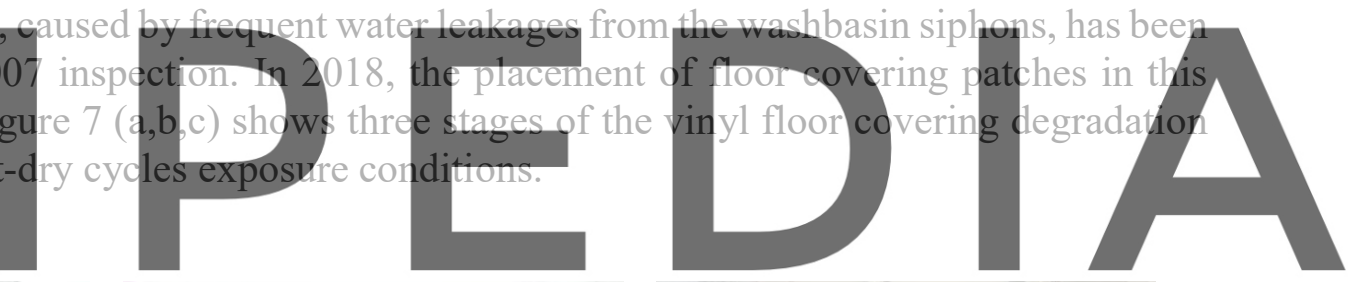

Register for free at https//www.scipedia.com to download thr

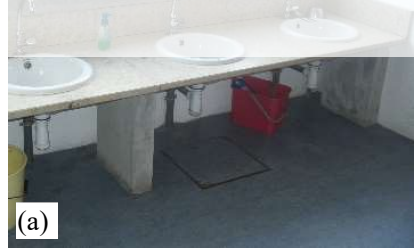

(b)
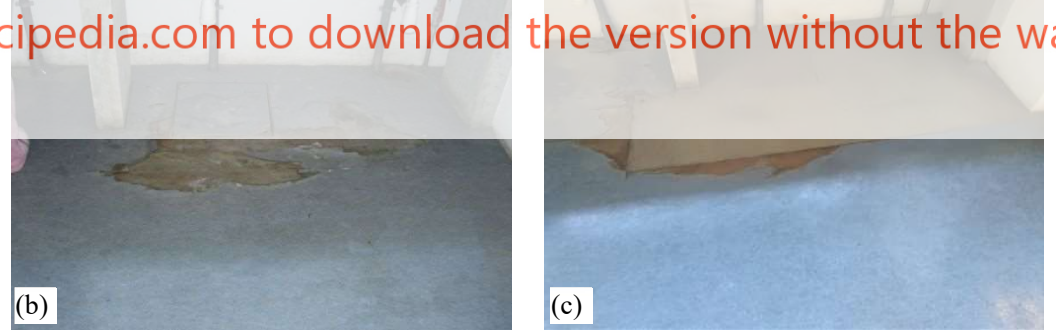

Figure 7. PRM School: vinyl floor degradation process caused by wet-dry cycles exposure conditions. Area in good condition and severely damaged area in 2007 (a,b); floor repaired in 2018 (c).

In the VA, AL, VG and PM Schools, cracks in interior to exterior walls and partitions walls were observed in 2018. In VA School, the severity and extent of the affected areas, indicates that the emergence of cracks is related to structural problems and differential settlements. In general, the most frequent anomalies in walls are related with deficient protection of corners and lack of adoption of wainscot/paneling elements in corridors and areas of intensive use.

Degradation in wall painting due to the use of adhesive tape for the exhibition of students' work was observed in the inspection carried out in 2007. In 2018 survey this anomaly was observed more frequently and over a larger area of walls (Fig. 8a). 
In ceilings, moisture and water ingress are the most frequent anomalies. Figure $8(\mathrm{~b}, \mathrm{c})$ shows the increased severity of this phenomenon in VA School, that may have resulted initially from lack or loss of waterproofing capacity of the building envelope (in 2007) and later resulted from the combination of several causes including building structural and foundations settlement problems (in 2018).
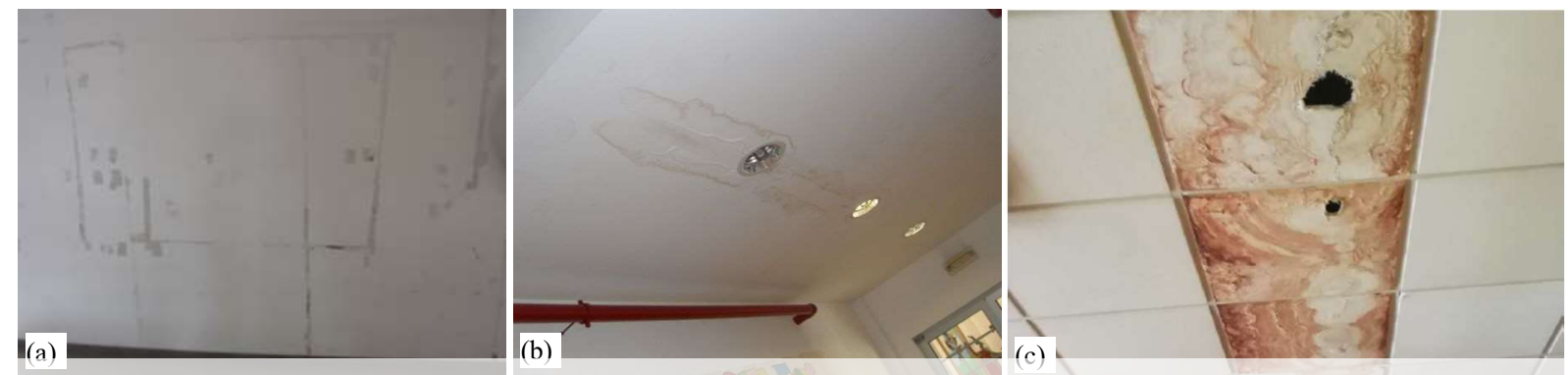

Figure 8. AF School: degradation in wall painting due to the use of adhesive tape for the exhibition of students work in 2018 (a). VA School: water infiltrations in the ceilings in 2007 (b) and in 2018 (c).

The model of the sliding doors used to separate the classrooms from the arts and crafts areas and in bathrooms (PRM, PM and AF Schools) presented several functional problems related to unsuitable serviceability, vertical misalignment and deficient fixation tracks causing localized wear on the floors finishes (Fig. 9a). The use of large bellows doors to separate the gym from school cafeteria is a widely used solution in these recent buildings schools. This solution ainds to open the spaces with Due to their characterist makes manual maneuveri because they require maintenance and repai
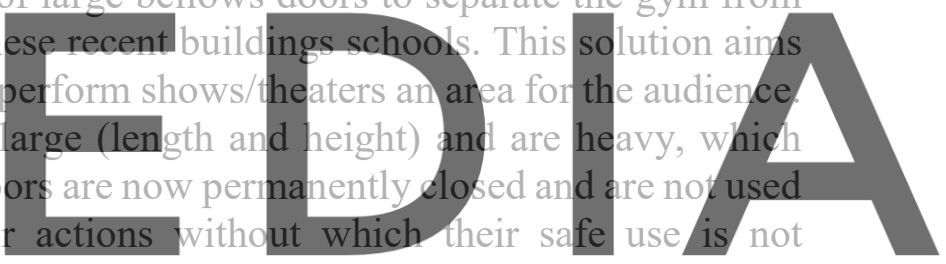

guaranteed (Fig. 9b). At PRM School, door closer need to be repaired in interior fire doors. In

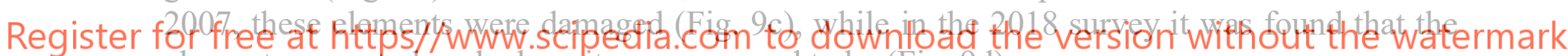
element was not placed where it was supposed to be (Fig. 9d).
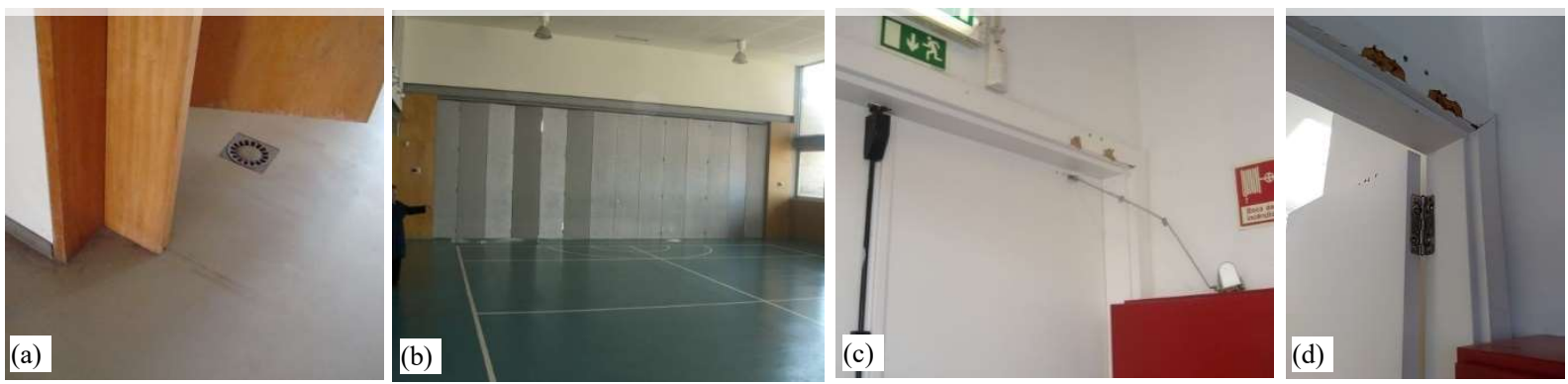

Figure 9. AF School: sliding door anomaly (a) non-operational bellows doors (b). PRM School: door closer anomaly in fire doors in 2007 (c) and 2018 (d).

\subsubsection{Sanitary services}

In 2018 survey, it was found that all schools continue to have recurrent problems and anomalies in the sanitary equipment and in the water supply and wastewater drainage networks. These installations are used intensively and not always in the most appropriate way. The most frequent 
anomalies in these systems continue to be (i) the breakdown of the toilet flushes, (ii) fixing problems of water faucets and (iii) problems with the drainage capacity of the wastewater network. The lack of proper maintenance and misuse, results in nonfunctional equipment and sometimes in floods. Figure 10 (a) shows the poor fixing of the water tap and deficient drainage of the wastewater, (b) failure in the flushing system causing waste of water and (c) anomaly in the floor box of the wastewater network.
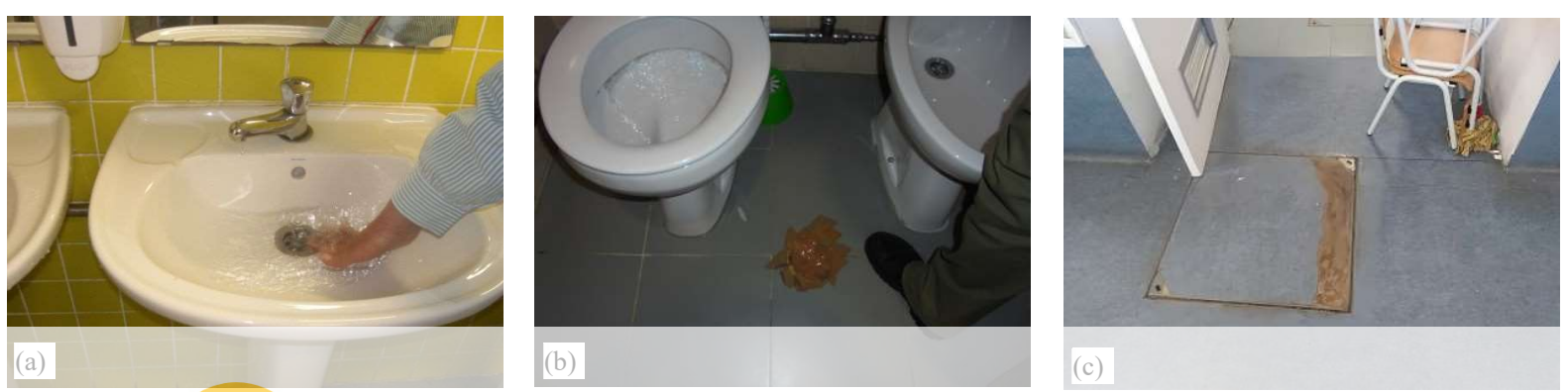

Figure 10. PRM School: anomalies on water tap and in the water flow, 2007 (a) failure in the flushing system, 2018 (b) and anomaly in the floor box covering finish of the wastewater network, 2018 (c).

\section{Conclusions}

This article presents the results of three inspections carried out in 2007, 2013 and 2018, on six school buildings buili a

degradation in these movements in the struct

(cracking in interior and showed that many of the execution and/or desion errors.
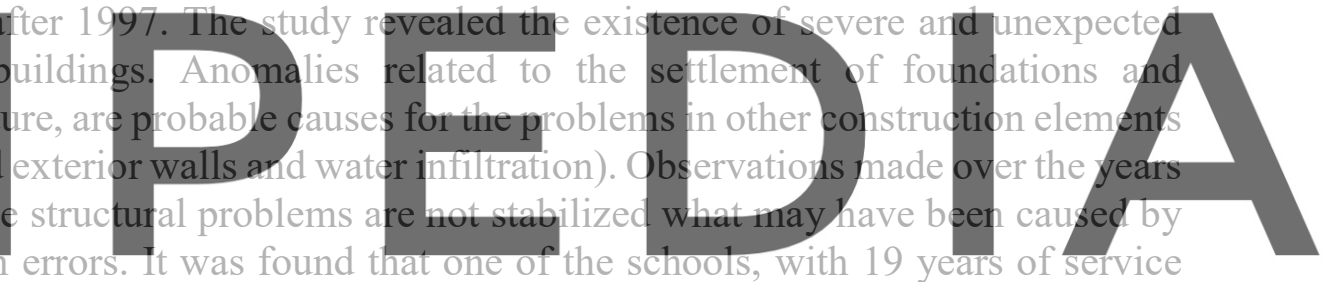

life, had to close, due to the existence of structural failures that endangered the health and safety

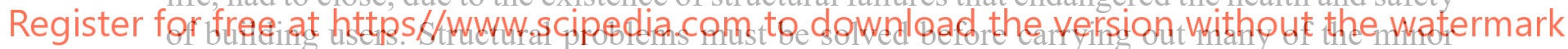

repairs, but they are complex, expensive, and so postponed.

Building schools should be designed to have a long service life, up from 50 years, so premature degradation of buildings is a problem with negative environmental, social and economic impacts. This work highlights the need for greater involvement of school building management entities, in the early stages of the building process, including design, tendering, construction and handover, to ensure that buildings and building elements fulfil their function for their specified design service lives.

\section{ORCID}

Sónia Raposo: https://orcid.org/0000-0002-7683-1391

\section{References}

Luís, J. (2013). Characterization of the degradation condition of the exterior building elements and outdoor spaces of school establishments in service (in Portuguese). Master Thesis, Universidade Técnica de Lisboa - Instituto Superior Técnico, Lisboa, Portugal. 
Nogueira, W. (2013). Characterization of the degradation condition of the interior building elements of school establishments in service (in Portuguese). Master Thesis, Universidade Técnica de Lisboa - Instituto Superior Técnico, Lisboa, Portugal.

Raposo, S., Fonseca, M. and Brito, J. (2008). Survey of the state of degradation of the school buildings of the Lisbon region. In Proceedings of the XI International Conference on Durability of Building Materials and Components, Istambul, Turkey, 1789-1796.

Raposo, S. (2011). The management of maintenance activity in public buildings. Model and strategies for a sustainable intervention (in Portuguese). PhD Thesis, Universidade Técnica de Lisboa - Instituto Superior Técnico, Lisboa, Portugal.

S478-19 (2019). Durability in buildings. Ontario, Canada: Canadian Standards Association.

Sousa, L., Ferreira, M., Mota de Sá, F., Oliveira, C., Raposo, S., Sigbjornsson, R., Rupakhety, R., Zonno, G., Meroni, F., Bianco, F. and D'Amico, S. (2012). Quantitative seismic risk evaluation and mapping: cases of schools and residential facilities in Lisbon and Algarve. In Proceedings of the 15th World Conference on Earthquake Engineering, Lisbon, Portugal, 8836-8845.

Vilhena, A., Vasconcelos, A., Batista Coelho, A., Vicente, M. and Raposo, S. (2019). Maintenance condition assessment of schools of the Municipality of Lisbon. Kindergarten and elementary schools (in Portuguese). Scientific Report 259/2019 - Laboratório Nacional de Engenharia Civil. Lisboa, Portugal.
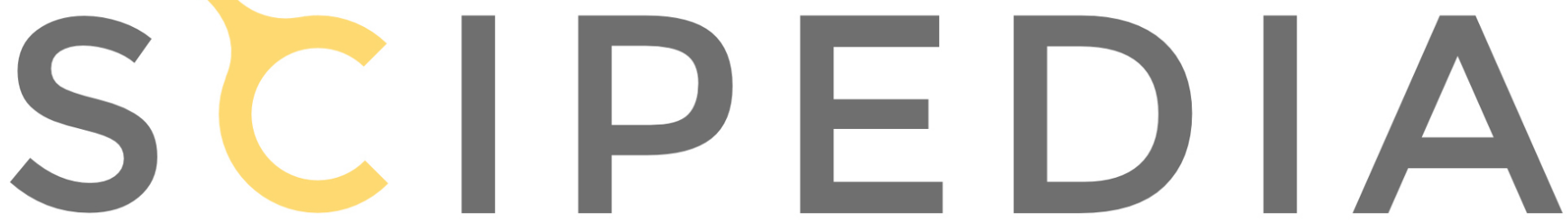

Register for free at https//www.scipedia.com to download the version without the watermark 